\title{
THE CARNEGIE INSTITUTION OF WASHINGTON
}

\author{
REPORT FOR 1957-58
}

$\mathrm{Y}$ EAR BOOK 57 of the Carnegie Institution of Washington* includes the President's and departmental and administrative reports for the year July 1, 1957-June 30, 1958, together with a bibliography of publications. Reviewing the work of the Institution, the president, Caryl $P$. Haskins, recalls that the year marked the tenth anniversary of the dedication of the 200-in. Hale telescope on Mount Palomar and of the joint operation of the Mount Wilson and Palomar Observatories by the Carnegie Institution of Washington and the California Institute of Technology. Both the presidential and the departmental reports briefly survey the work of the decade and the important advances in knowledge, particularly in our ideas of the size of the observable universe, the magnitudes of the distances within it, and its age, and in our knowledge of stellar evolution.

During the year the magnetic classification and study of sunspots and related phenomena continued, and a series of direct photographs of the bright comet Mrkos (1957d) was obtained with the 48 -in. Schmidt telescope. An extensive project on the chemical composition of stellar atmospheres is in progress and a survey of high-dispersion spectra of the early carbon stars has revealed differences in both the line and the band spectra. Coudé spectrograms with a resolution of $10 \mathrm{~A} . / \mathrm{mm}$., or better, are being accumulated to obtain evidence bearing on mass loss from late-type giants and super-giant stars, and the investigation of the internal motion of nebulæ using the multislit technique and a dispersion of $4.5 \mathrm{~A} . / \mathrm{mm}$. at the 200-in. coudé continued. Work on the colourmagnitude diagram of the Draco system showed that the diagram is of the same type as that of the globular clusters of the galactic halo and conforms to the rule that large numbers of cluster-type variables can only be expected if the horizontal branch on the red side of the variable gap is strongly populated. The direct photography of multiple galaxies continued, and also the investigation of objects which might be associated with radio sources. A theoretical investigation was conducted by the properties of the very luminous $O B$ stars observed by Code and Houck, and a preliminary model of a photoelectric spectrum-scanning device was tried on the coudé spectrograph of the 100-in. telescope. The Committee on Image Tubes for Telescopes has continued to encourage the development of photoelectric imageintensifying devices for use in astronomy, directing attention both to methods that record the photoelectrons themselves and to methods that use photoelectrons to produce an optical effect.

The Department of Terrestrial Magnetism continued its study of the emission of energy at radio frequencies from celestial objects, but solar activity of unprecedented magnitude interfered seriously with optical red-shift measurements of the far-distant galaxies at Mount Wilson and Palomar, although * Carnegie Institution of Washington. Year Book No. 57, July 1, 1957-June 30,1958 . Pp. xi $+497+12$ plates. (Washington, D.C.: Carnegie Institution, 1958. 1 dollar, paper bound ; 1.50 dollars, cloth bound. work proceeded rapidly on precision equipment designed to measure the position of radio sources to within a few square minutes of arc. The density distribution and velocity distribution of atomic hydrogen gas clouds in our galaxy continued to be of major interest to the radio astronomy group, while three noteworthy projects were carried forward as part of the programme of the International Geophysical Year: the study of the intense band of electric current, called the electro jet, that circulates in the upper atmosphere in the region of the Earth's magnetic equator ; a study of the Earth's crust in the Andean highlands at more than 200 sites, utilizing explosions normally set off in operating large openpit copper mines; and the measurement of the ages of rock minerals through the methods provided by the study of radioisotopes, notably the geographical patterns of the ages of Precambrian rocks in North America, particularly the metamorphic Precambrian rocks of the central and southern Appalachians. A general picture of the geological history of the Appalachian orogenic belt has emerged.

The Geophysical Laboratory has construeted new equipment of rather revolutionary design for studying geochemical and geophysical phenomena: with a new 'single-stage' apparatus, pressures of up to 50,000 atmospheres at temperatures up to $1,700^{\circ} \mathrm{C}$. have been achieved, and in the two-stage design, in which the piston of the single-stage apparatus is supported, up to 65,000 atmospheres at $1,100^{\circ} \mathrm{C}$. The single-stage apparatus is being used to study the influence of pressure on the melting-points of minerals that might exist 80 miles below the Earth's surface. Work on mineral assemblages in the Green River formation, on the beneficial effect of potassium on soils contaminated with strontium-90, on the effect of water on the melting of silicates and on the biotites is reported in some detail, as well as work on feldspar, ore minerals of the sulphide type and on the diffraction effects of short-range ordering in layered sequences. In crystallography the magnetic structure of chalcopyrite has been determined by neutron diffraction studies and a crystallographic study was made of arsenopyrite by X-ray diffraction methods.

Five of the Institution's seven departments are concerned with biological investigations of one kind or another. The Geophysical Laboratory, for example, has investigated the detection of organic materials in Precambrian rocks and has significantly increased the yields of organic materials from processed shales such as Swedish Kolm shale (Cambrian), Nevadan Vanini shale (Ordovician) and Colorado Green River shale (Eocene). In the Biophysics Group of the Department of Terrestrial Magnetism attention has been focused particularly on the critical importance in metabolism and growth of the elaborate and precise fine structure of many of the constituents of the living cell. The properties of the ribosomes and the kinetics of their formation have been studied by ion-exchange columns, radioactive-tracer methods and the 'Spinco' Model $L$ centrifuge. Work with Escherichia coli is described in some detail, while, 
besides studies on virus purification, extensive work on amino-acid analogues continued with particular emphasis on determining whether the analogues are contained in radically different molecular species or in proteins similar to those normally synthesized.

Measurements in the Department of Plant Biology on the derivative absorption spectra of chlorophyll in numerous algae and other plants suggest that there are more than two forms of chlorophyll $a$. Further investigation on the photochemical formation of chlorophyll in leaves from its precursor photochlorophyll gave yields of about $0 \cdot 5-0 \cdot 7$ molecule of chlorophyll formed per quantum of light absorbed, suggesting that two quanta of light may produce one molecule of chlorophyll. A study of the reversible oxidative bleaching of chlorophyll by chemical treatment and by light in several species of photosynthetic bacteria showed that the chemical properties of the pigment are markedly influenced by its incorporation in natural structures, the form absorbing light at the longest wave-length $(890 \mathrm{~m} \mu)$ being the most active. A number of climatic races of Mimulus plants are being grown for laboratory studies of the way their rates of respiration respond to variations of temperature and intensity of light, and studies have been commenced on the germination of seedling populations of contrasting parental and hybrid lines of Mimulus under crossed gradients of controlled temperature and light intensity.

In the Department of Embryology, studies of the molecular basis of rhythmic motility in spermatozoa indicated that the mechanisms of contractility and co-ordination ean be disengaged experimentally. Important findings are reported in work on the development of the adrenals and sympathetic paraganglia in insectivores, and studies on the synthesis of the muscle proteins actomyosin and myosin in the regenerating limb of the salamander continued. Other work was concerned with differentiation and morphogenesis in the human embryo, the neural crest and its derivatives, the chemical basis of morphogenetic movements, the acquisition of biological specificity, the effect of hormones in developmental systems, and the anatomy and physiology of the uterus and the placenta.

In the Department of Genetics, studies with maize clarified an obscure aspect of the suppressor-mutator system of control of gene action, and analyses of biological ultrastructure by methods combining cytochemistry and electron microscopy offered new evidence that the chromosomes in actively dividing cells contain ribonucleic acids at all stages of the mitotic cycle. Studies of the intracellular deoxyribo. nucleases were concentrated on ascertaining the best procedures for extracting and purifying the intracellular deoxyribonuclease of salmon testes. Further studies of the properties of phage $T 2$, which grows on strain $B$ of Escherichia coli, suggest that phage particles are made from at least two protein sub-units, each containing a large fraction of the total phage sulphur. Studies of bacterial geneties with Salmonella typhimurium and Escherichia coli support the assumption that recombination among five genetic markers in the former is accomplished through a 'copy-choice' mechanism governing the exchange of characters between a recipient chromosome and a transducing element, and that the frequency of 'switchovers' in this process depends on the genetic constitution of the chromosome regions. Evidence has been obtained that transduction by bacteriophage lambda of loci concerned with galactose utilization in $E$. coli is a matter of lysogenization by a new type of genetic structure, which is part phage and part bacterial in origin.

The Department of Archæology completed its work during the year, and both the departmental and the presidential reports review broadly its work over more than fifty years. Some notes on ceramic studies in Yueatan and a ceramic technology are included in the departmental report.

\section{THE NATIONAL RESEARCH DEVELOPMENT CORPORATION REPORT FOR 1957-58}

\begin{abstract}
$\mathrm{T}$ HE report of the National Research Development Corporation for the year ended June 30, 1958*, records a revenue from inventions of $£ 174,242$, notably from triiodothyronine, Prof. R. L. Wain's phenoxybutyric acid weed-killers, the Bailey bridge, the Royal Aircraft Establishment fire and heat detector and gyroscopic control apparatus for aircraft, the Ministry of Supply electrical ignition system and exploder, anti-thyroid compounds, the Hutchinson-Scarrott pulse height analyser, hecogenin from sisal, the Denny-Brown ship stabilizer control gear, nisin and anti-tumour agents of the nitrogen mustard type, on which all significant expenditure has ceased. Further reference is made to the Corporation's part in the development of electronic digital computers, including a project for the development of a large business-type computer and data-processing system of advanced design and performance, making extensive use of transistors, and two projects for mag-
\end{abstract}

* National Research Development Corporation. Report and Statement of Accounts for the year 1st July, 1957, to 30th June, 1958. Pp. ii 128 . (London: H.M. Stationery Office, 1958.) 1s. 6d. net. netic type equipment for use with digital computers, but progress with the development of a very high. speed computer has been slow. An agreed programme of research and development of computer-controlled machine tools was initiated at the Manchester College of Science and Technology in January 1956, and interesting results are being obtained on the performance of slideways and on the cutting forces occurring during contour milling operations. Work continues on the development of high-performance drive systems, but the Corporation now considers that the time has come to withdraw its financial support.

Work at the National Physical Laboratory on Sir Thomas Merton's diffraction grating inventions is proving important in unexpected ways, and the Corporation's intervention in the development of printed electrical circuits has also been fully justified by results. The Corporation has now been able to retire from the collaborative effort it initiated seven years ago, leading to the collection of pituitary gland and production of adrenocorticotropic hormone on a commercial basis. Development of a process for 